\title{
Risk factors associated with ischemic heart disease occurence in acute ischemic stroke patients
}

\author{
Michal Kovacika, ${ }^{\mathrm{a}}$, Stefan Madarasz ${ }^{\mathrm{b}}$, Michal Kral ${ }^{\mathrm{a}}$, Tomas Veverka ${ }^{\mathrm{a}}$, Roman Herzig ${ }^{\mathrm{a}}$, Petr Kanovsky ${ }^{\mathrm{a}}$
}

\begin{abstract}
Aims. At specific time periods following ischemic stroke (IS), acute coronary syndrome as ischemic heart disease (IHD) represents a higher risk of death than IS. Not all IS patients can undergo specific examination for IHD detection. The aim of this study was to assess exclusive risk factors (RFs) associated with IHD occurrence in IS patients. Knowledge of these RFs should help in stratifying IS patients for IHD detection.

Materials and methods. This was a hospital-based, retrospective, single centre study. The sample consisted of 192 consecutive IS patients, divided into two subgroups - Subgroup 1 (54 patients without IHD; $55.6 \%$ males; $63.1 \pm 11.8$ years) and Subgroup 2 (138 patients with IHD; 39.1\% males; $76.3 \pm 9.6$ years). The following factors were identified: age; sex; presence of arterial hypertension, atrial fibrillation, diabetes mellitus; plasma levels of total cholesterol, triglycerides, low-density cholesterol, high-density cholesterol; body mass index; presence of carotid plaques. Logistic regression analysis was used for statistical evaluation.

Results. Of all identified risk factors only age $(\mathrm{OR}=1.109 ; 95 \% \mathrm{Cl}: 1.069-1.150, P=0.001)$ and the presence of arterial hypertension ( $\mathrm{OR}=6.298 ; 95 \% \mathrm{Cl}: 2.215-17.905, P=0.003)$ were exclusively and significantly associated with the presence of IHD in IS patients.

Conclusions. Age and arterial hypertension may be exclusive risk factors associated with IHD in IS patients.

Key words: ischemic heart disease, ischemic stroke, epidemiology, risk factors

Received: July 2, 2011; Accepted with revision: December 9, 2011; Available online: January 30, 2012

http://dx.doi.org/10.5507/bp.2011.069

${ }^{a}$ Comprehensive Stroke Centre, Department of Neurology, Faculty of Medicine and Dentistry, Palacky University Olomouc and University Hospital Olomouc, Czech Republic

${ }^{b}$ Department of Neurology, Central Military Hospital, Ruzomberok, Slovakia

Corresponding author: Michal Kovacik, e-mail: michal22kovacik@gmail.com
\end{abstract}

\section{INTRODUCTION}

Ischemic stroke (IS) patients are mainly endangered by stroke recurrence in the first 2 years after the onset of IS (ref. ${ }^{1}$ ). After this period, coronary death due to ischemic heart disease (IHD), is the main cause of the long-term mortality in IS patients, with an incidence of $1.5-5.4 \%$ p.a. $\left(\right.$ ref $\left.^{2-5}\right)$. Thus, a great deal of effort is devoted to IHD identification and its proper management ${ }^{6-8}$. It is not clear to date, why IHD is present only in some IS patients and not in others, ${ }^{9}$. IHD and IS traditional risk factors have been well-studied and documented individually on large prospective cohorts ${ }^{11-15}$ and there are new studies appearing. In the majority of cases, these risk factors are same for both entities. Atherosclerosis plays a crucial role both in the development of IHD and IS. Nevertheless, IS pathophysiology and etiology are far more complex and atherosclerosis represents just one of several causes. There are also differences in atherosclerosis itself and atherosclerosis may differ in intracranial and extracranial portions of the internal carotid artery ${ }^{16,17}$.

The aim of the present study was to identify the exclusive risk factors associated with IHD occurrence in IS patients. Identification of these risk factors and their proper management may lead to decrease in the occurrence of IHD in IS patients, and to the better long-term clinical outcome of IS patients.

\section{MATERIALS AND METHODS}

A retrospective, hospital based, single centre study was used. Discharge reports of 192 consecutive patients with documented IS admitted to the Department of Neurology, Hospital Liptovský Mikuláš, Slovakia, from December 2007 to January 2009 were systematically reviewed.

IS diagnosis was based on clinical findings and computed tomography (CT) results (presence of neurological deficit and corresponding acute ischemic area on CT or magnetic resonance imaging) according to the WHO criteria $^{18}$ and latest diagnostic progress ${ }^{19}$. Diagnosis of clinically manifest IHD was made by a senior internal medicine specialist based on the clinical (history of myocardial infarction) and electro-cardiographic (ECG) findings (ST segment changes, presence of Q wave) $\left(\right.$ ref $\left.^{20}\right)$. According to the IHD presence, IS patients were divided in two subgroups.

The following risk factors were identified: age; sex; presence of arterial hypertension (AH - either previously established diagnosis or repeated blood pressure values > $140 / 90 \mathrm{~mm} \mathrm{Hg}$ after the period of acute stroke), atrial fibrillation on ECG, diabetes mellitus (either previously established diagnosis or fasting blood glucose $\geq 6.1 \mathrm{mmol} / \mathrm{l}$ ); plasma levels of total cholesterol ( $\mathrm{mmol} / \mathrm{l})$, triglycerides $(\mathrm{mmol} / \mathrm{l})$, low-density cholesterol ( $\mathrm{mmol} / \mathrm{l})$, high-density cholesterol (mmol/l); body mass index (weight/height ${ }^{2}$ ); 
presence of more than $50 \%$ carotid stenosis on ultrasound examination, smoking (more than 10 pack/years). Due to extensive missing data regarding smoking, smoking was excluded from statistical evaluation.

In order to control the confounding factors, multivariable logistic regression analysis (SAS Institute Inc., Cary, NC, USA) was used to identify the exclusive risk factors associated with IHD occurrence in IS patients. Odds ratios for the statistically significant risk factors with a confidence interval of $95 \%$ were calculated.

\section{RESULTS}

Based on the previously mentioned criteria, 192 consecutive IS patients were included in the study and divided into two subgroups. Fifty-four patients (55.6\% males; 63.1 \pm 11.8 years) had a negative IHD history (Subgroup 1), while the history of IHD was present in 138 patients (39.1\% males; $76.3 \pm 9.6$ years) (Subgroup 2). All patients were Caucasians. Comparisons of the occurrence of the identified factors in the particular subgroups are shown in (Table 1).

Odds ratios for evaluation of independent association of particular risk factors and IHD occurrence were calculated using the logistic regression statistical model. Of all the observed risk factors included in the statistical model, only age $(\mathrm{OR}=1.109 ; 95 \% \mathrm{CI}: 1.069-1.150, P=0.001)$ and the occurrence of $\mathrm{AH}(\mathrm{OR}=6.298 ; 95 \% \mathrm{CI}: 2.215$ $17.905, P=0.003$ ) were significantly associated with the IHD presence in IS patients - see (Table 2). No other risk factors showed any significant relationship to IHD in IS patients and the odds ratios could not be established.

The association between the occurrence of IHD in IS patients in terms of age and the presence of $\mathrm{AH}$ is shown in (Fig. 1). Derived from this relation, a 60-year-old IS patient would have $10 \%$ probability of IHD presence in the case of $\mathrm{AH}$ absence. Theoretically, if the same patient was 9.3 years older and had $\mathrm{AH}$, his chance of IHD would be $75 \%$. This example illustrates, how strong the correlation between $\mathrm{AH}$ and IHD presence is.

\section{DISCUSSION}

Risk factors for atherosclerosis which plays a crucial role in the development of both IHD and IS, have already had been well-studied ${ }^{11-15}$. However, IHD and IS represent different nosological entities. The prognosis is poorer in patients with coincidental occurrence of these two diagnoses ${ }^{9}$. To date, one cannot clearly predict, whether an IS patient also suffers from IHD and or not. Knowledge of which risk factors are exclusively associated with IHD occurrence in IS patients, could help to identify the patients at higher risk.

In the presented study, a correlation between age and the AH occurrence was found. The strength of the association was quite strong in the case of $\mathrm{AH}(\mathrm{OR}=6.298)$, but weaker in the case of age $(\mathrm{OR}=1.109)$. None of the remaining risk factors were associated with IHD occurrence. This finding may be explained by the etiological complexity of IS. Atherosclerosis plays a major role in IHD as well as IS development, but in IS stroke the situation is far more complex and other etiologies play a significant role too (e.g. cardio-embolism, small vessel disease, thrombophilia) $)^{11-15}$.

In the presented study, AH was shown to be the strongest risk factor for IHD occurrence in IS patients. AH was repeatedly reported to be a strong individual risk factor for both IHD and IS ${ }^{11-15}$. However, AH seems to be more strongly related to IHD than to IS. The etiological complexity of IS might be an explanation.

There are several etiological subtypes of IS (AH represents a risk factor in only some of them), while IHD is predominantly caused by atherosclerosis in which $\mathrm{AH}$ plays major role ${ }^{12,21}$. Schultz and Rothwell ${ }^{22}$ showed in their meta-analysis of two population based stroke incidence studies involving more than 196000 patients, that vascular risk factors differ between the IS subtypes. In this meta-analysis, AH was surprisingly associated only with small vessel disease subtype of IS and not even with the atherosclerotic type. In this meta-analysis only the cardioembolic subtype of IS showed an association with atherosclerosis. In the Erlangen study ${ }^{23}, \mathrm{AH}$ even showed a



Fig. 1. Ischemic heart disease presence in ischemic stroke patients according to the age and the arterial hypertension occurrence. 
Table 1. Characteristics of the study participants and occurrence of the observed risk factors.

\begin{tabular}{lcc}
\hline Characteristic & stroke and no CAD & stroke and CAD \\
\hline Study participants - no. & 54 & $54(39.1)$ \\
Males - no. (\%) & $30(55.6)$ & $76.3 \pm 9.6$ \\
Age - years & $63.1 \pm 11.8$ & $28.5 \pm 5.7$ \\
BMI - (kg/m $\left.{ }^{2}\right)$ & $30.4 \pm 4.2$ & $5.0 \pm 1.3$ \\
Plasma level & & $1.6 \pm 1.1$ \\
Total cholesterol - (mmol/L) & $5.5 \pm 1.5$ & $3.3 \pm 1.4$ \\
TG - (mmol/L) & $1.9 \pm 1.2$ & $1.2 \pm 0.4$ \\
LDL - (mmol/L) & $3.5 \pm 1.1$ & $124(89.9)$ \\
HDL - (mmol/L) & $1.3 \pm 0.6$ & $51(37)$ \\
Arterial hypertension - no. (\%) & $36(66.7)$ & $9(6.5)$ \\
Diabetes mellitus - no. (\%) & $14(25.9)$ & $55(39.9)$ \\
Carotid stenosis $>$ 50 $\%$ no. (\%) & $1(1.9)$ & \\
Atrial fibrillation - no. (\%) & $0(0)$ & \\
\hline
\end{tabular}

Plus-minus values are means \pm standart deviation, CAD denotes coronary artery disease, BMI - body mass index, TG - triglicerides, LDL-CH - low density lipoproteins, HDL - high densitz lipoproteins, no - number

Table 2. Risk factors associated with the ischemic heart disease presence in ischemic stroke patients.

\begin{tabular}{lccc}
\hline Risk Factor & Odds Ratio & $95 \%$ Confidence Interval & $P$ value \\
\hline Age (1 year) & 1.11 & $1.07-1.15$ & 0.001 \\
Arterial hypertension & 6.23 & $2.26-17.91$ & 0.003 \\
\hline
\end{tabular}

IHD denotes ischemic heart disease, IS - ischemic stroke

negative correlation (with RR of 0.8) in the subtype of IS with undetermined etiology, representing approximately $40 \%$ of all ischemic strokes ${ }^{22,23}$. Thus the relation between $\mathrm{AH}$ and ischemic stroke is much weaker, than it is in IHD.

Age is another independent risk factor associated both with IS and IHD, when considered individually ${ }^{24}$. In the presented study, age was also shown to be an independent predictor of IHD occurrence in IS patients. However this correlation was rather weak. As the process of atherosclerosis develops over time, the incidence of IHD also increases with advanced age ${ }^{25}$. Thus, age is a logical risk factor for IHD presence in IS.

In previous studies ${ }^{26-29}$ atrial fibrillation and carotid stenosi ${ }^{30}$ showed positive correlation to IHD presence in IS patients. However study design and primary goals were different to this study. Moreover, this difference could be due to retrospective design and sample size of patients in the presented study. These factors also represent the main limitations of the study.

In the present study, the diagnosis of IHD was based upon clinical and ECG findings, as used in everyday clinical practice, not on the basis of radiological findings, such as coronarography, as used in previous studies $^{7-10}$ or laboratory findings as emerging studies suggest. Coronarography is a very sensitive and specific method for evaluation of degree of coronary stenosis. However it does not reveal anything about the clinical state of the patient since many stenoses are asymptomatic. Additionally, coronarography itself is associated with peri and postprocedural risks, radiation load and not all IS patients can undergo the examination. Thus for IHD identification in this study, clinical and ECG findings were used. The idea behind the whole study was to identify patients at risk for IHD presence in terms of risk factors, and those patients sent to coronarography, in order to confirm the suspicion.

Beside traditional risk factors, which were found in the present study, rarer risks such as thrombophilia, Wegener's granulomatosis and oral contraception intake have been described ${ }^{31,32}$. Risk factors for stroke also differ in young and older patients ${ }^{33}$. However, despite their great clinical impact, the incidence is low. Thus these rare risk factors were not found in this study.

The present study, despite its limitations, provides new insight into the role of risk factors in two major vascular diseases. Identification of risk factors exclusively associated with IHD in IS patients is an important goal for further studies. 


\section{CONCLUSIONS}

Age and the presence of $\mathrm{AH}$ were identified as probable risk factors for IHD in IS patients in this study. However, further well-designed studies are needed to confirm these pilot results.

\section{ABBREVIATIONS}

$\mathrm{AH}$, arterial hypertension; CT, computed tomography; ECG, electrocardiography; IHD, ischemic heart disease; IS, ischemic stroke; OR, odds ratio; RFs - risk factors; WHO - world health organization.

\section{REFERENCES}

1. Kovacik M, Madarasz S, Bartko D, Pesta M, Herzig R, Kanovský P. Cievna mozgová príhoda a ischemická choroba srdca. Cesk Slov Neurol N 2010;73:497-502

2. ESPS group: European stroke prevention study. Stroke 1990; 21:1122-30.

3. Hass WK, Easton JD, Adams HP Jr, Pryse-Phillips W, Molony BA, Anderson S, Kamm B. A randomized trial comparing ticlopidine hydrochloride with aspirin for the prevention of stroke in high-risk patients. N Engl J Med 1989;321:501-7.

4. Diener HC, Cunha L, Forbes C, Sivenius J, Smets P, Lowenthal A. European stroke prevention study 2, dipyridamole and acetylsalicylic acid in the secondary prevention of stroke. J Neurol Sci 1996;143:1-13.

5. CAPRIE Steering Committee. A randomised, blinded, trial of clopidogrel versus aspirin in patients at risk of ischaemic events (CAPRIE). Lancet 1996;348:1329-39.

6. Adams RJ, Chimowitz MI, Alpert JS, Awad IA, Cerqueria MD, Fayad $\mathrm{P}$, Taubert KA. Coronary risk evaluation in patients with transient ischemic attack and ischemic stroke: A scientific statement for healthcare professionals from the Stroke Council and the Counci on Clinical Cardiology of the American Heart Association/American Stroke Association. Stroke 2003;34:2310-22.

7. Hoshino A, Nakamura T, Enomoto S, Kawahito H, Kurata H, Nakahara $Y$, ljichi T. Clinical utility of evaluating intracranial artery stenosis and silent brain infarction to predict the presence of subclinical coronary artery disease in ischemic stroke patients. Intern Med 2008;47:177581.

8. Griva M, Naplava R, Spendlikova M, Jarkovsky J, Hlinomaz O, Cihalik C. Potential role of selected biomarkers for predicting the presence and extent of coronary artery disease. Biomed Pap Med Fac Univ Palacky Olomouc Czech Repub 2010;154:219-25.

9. Fischer U, Arnold M, Nedeltchev K, Schoenenberger RA, Kappeler L, Hoellinger P, Schroth G, Ballinari P, Mattle HP. Impact of comorbidity on ischemic stroke outcome. Acta Neurol Scand 2006;113:108-13.

10. Hoshino A, Nakamura T, Enomoto $S$, Kawahito $H$, Kurata $H$, Nakahara Y, ljichi T. Prevalence of coronary artery disease in Japanese patients with cerebral infarction: impact of metabolic syndrome and intracranial large artery atherosclerosis. Circ J 2008;72:404-8.

11. Helfand M, Buckley DI, Freeman M, Fu R, Rogers K, Fleming C, Humphrey LL. Emerging risk factors for coronary heart disease: a summary of systematic reviews conducted for the U.S. Preventive Services Task Force. Ann Intern Med 2009;151:496-507.

12. O'Donnell MJ, Xavier D, Liu L, Zhang H, Chin SL, Rao-Melacini $P$ Rangarajan S, Islam S, Pais P, McQueen MJ, Mondo C, Damasceno A, Lopez-Jaramillo P, Hankey GJ, Dans AL, Yusoff K, Truelsen T, Diener HC, Sacco RL, Ryglewicz D, Czlonkowska A, Weimar C, Wang X, Yusuf $\mathrm{S}$; INTERSTROKE investigators. Risk factors for ischaemic and intracerebral haemorrhagic stroke in 22 countries (the INTERSTROKE study): a case-control study. Lancet 2010;376:112-23.
13. Nomura E, Kohriyama T, Matsumoto M, Kobayashi S. Clinical characteristics of first-ever atherothrombotic infarction or lacunar infarction with hyperlipidemia (J-STARS-C): an analysis of data from the stroke data bank of Japan Intern Med 2005:44:1252-7.

14. Suzuki A, Kosuge K, Nanyu O, Watanabe H, Watanabe T, Usuda Y, Sasaki S, Aizawa Y. Five year study of cardiovascular risk factors in Japanese people: implications concerning new onset of metabolic syndrome. Intern Med 2010;49:1-6.

15. Nakládalová $M$, Sovová E, Ivanová K, Kaletová M, Lukl J, Fialová J. Risk factors for cardiovascular diseases in physicians. Biomed Pap Med Fac Univ Palacky Olomouc Czech Repub 2005;149:293-5.

16. Watanabe M, Kimura K, Iguchi Y, Shibazaki K, Urabe T, Hattori N. Peripheral arterial atherosclerosis in patients with extracranial, not intracranial, arterial stenosis. Intern Med 2010;49:1515-9.

17. Halenka M. Noninvasive measurement of early atherosclerosis by high-resolution B-mode ultrasonography. Acta Univ Palacki Olomuc Fac Med 1999;142:7-11.

18. Aho K, Harmsen P, Hatano S, Marquardsen J, Smirnov VE, Strasser T. Cerebrovascular disease in the community: results of a WHO collaborative study. Bull World Health Organ 1980;58:113-30.

19. Hashimoto $Y$, Hirano T, Terasaki T, Yonehara T, Uchino M. Therapeutic strategy for acute stroke prologue for an epoch of brain attack. Progress of diagnosis of acute stroke. Intern Med 2005;44:360-2.

20. Tunstall-Pedoe $H$, Kuulasmaa $K$, Amouyel $P$, Arveiler $D$, Rajakangas AM, Pajak A. Myocardial infarction and coronary deaths in the World Health Organization MONICA Project. Registration procedures, event rates, and case-fatality rates in 38 populations from 21 countries in four continents. Circulation 1994;90:583-12.

21. Bamford J, Sandercock P, Jones $L$, Warlow $C$. The natural history of lacunar infarction: the Oxfordshire Community Stroke Project Stroke 1987; 18:545-51.

22. Schulz UGR, Rothwell PM. Differences in vascular risk factors between etiological subtypes of ischemic stroke. Stroke 2003;34:2050-

23. Kolominsky-Rabas PL, Sarti C, Heuschmann PU, Graf C, Siemonsen S, Neundoerfer B, Katalinic A, Lang E, Gassmann KG, Ritter von Stockert T. A prospective community-based study of stroke in Germany - The Erlangen Stroke Project (ESPro): Incidence and case Fatality at 1, 3, and 12 months. Stroke 1998;29:2501-6.

24. Thrift AG, Dewey HM, Macdonell RAL, McNeil JJ, Donnan GA. Incidence of the major stroke subtypes. Stroke 2001;32:1732-8.

25. Lakatta EG, Levy D. Arterial and cardiac aging: Major shareholders in cardiovascular disease enterprises: Part I: Aging arteries: A "set up" for vascular disease. Circulation 2003;107:139-46.

26. Tanimoto S, Ikari Y, Tanabe K, Yachi S, Nakajima H, Nakayama T, Hator M, Nakazawa G, Onuma Y, Higashikuni Y, Yamamoto H, Tooda E, Hara K. Prevalence of carotid artery stenosis in patients with coronary artery disease in Japanese population. Stroke 2005;36:2094-8.

27. Kallikazaros I, Tsioufis C, Sideris S, Stefanadis C, Toutouzas P. Carotid artery disease as a marker for the presence of severe coronary artery disease in patients evaluated for chest pain. Stroke 1999;30:1002-7.

28. Nucifora G, Schuijf JD, Tops LF, Werkhoven JM, Kajander S, Jukema JW, Schreur JHM, Heijenbrok MW, Trines SA, Gaemperli O, Turta O, Kaufmann PA, Knuuti J, Schalij MJ, Bax JJ. Prevalence of coronary artery disease assessed by multislice computed tomography coronary angiography in patients with paroxysmal or persistent atrial fibrillation. Circ Cardiovasc Imaging 2009;2:100-6.

29. Ogata T, Yasaka M, Wakugawa Y, Yasumori K, Kitazono T, Okada Y. Prognosis of medical treatment for Japanese patients with carotid stenosis. Intern Med 2011;50:291-6.

30. Touzé E, Warlow CP, Rothwell PM. Risk of coronary and other nonstroke vascular death in relation to the presence and extent of atherosclerotic disease at the carotid bifurcation. Stroke 2006:37:2904-9.

31. Bares M, Muchová M, Dufek M, Litzman J, Krupa P, Rektor I. Wegener's granulomatosis - ischemic stroke as the first clinical manifestation (case study). J Neurol 2002;249:1593-4.

32. Zakharova MY, Meyer RM, Brandy KR, Datta YH, Joseph MS, Schreiner PJ, Rao GH, Divani AA. Risk factors for heart attack, stroke, and venous thrombosis associated with hormonal contraceptive use. Clin Appl Thromb Hemost 2011;17:323-31.

33. Balci K, Utku U, Asil T, Celik Y. Ischemic stroke in young adults: risk factors, subtypes, and prognosis. Neurologist 2011;17:16-20. 